\title{
The overview analysis of the movie Sense and Sensibility
}

\author{
Nyak Mutia Ismail ${ }^{1 *}$ \& Moriyanti ${ }^{2}$ \\ ${ }^{1}$ Syiah Kuala University, Indonesia \\ 2Iskandarmuda University, Indonesia \\ *Corresponding author \\ Email: nyakmutiaismail2010@gmail.com
}

\begin{abstract}
Movies have been everybody's favorite across all ages. Some movies are not suitable for certain ages and the parents' assistance is needed during the watching movie process so that they can show the morals conceived in the movie. This study tries to shed lights on the elements contained in a movie entitled "Sense and Sensibility", a movie made based on a novel by Jane Austen. This study was carried out in qualitative approach using visual feature analysis technique. The object of this study was the movie with the duration of 140 minutes. The data obtained were then classified based on its elements such as realism, local color, narratives, and symbolism. The result portrayed that the realism given in this movie is the condition of a noble family who had lost all of their wealth and life had been becoming crude. The local color depicts the social status in the mid-eighteenth century. The story was narrated in the linear plot and finally, the symbolism in this movie exposed much about the calming and melancholic nature of Devonshire.
\end{abstract}

Keywords: movie analysis, sense and sensibility, realism, local color, symbolism.
Received:
Revised:
Accepted:
Published:
1 June 2018
18 August 2018
28 February 2019
28 February 2019

\section{INTRODUCTION}

Nowadays, there have been a lot of digital movies available on television and internet. Undeniably, people need amusement and watching movies have been an effortlessly relieving amusement full days of working and other responsibilities. The challenges then emerge, especially for children or teenagers who find it hard to find meaningful movies and videos to watch (Vassiliou, 2006). Parents also come as the general stakeholders in helping their children filter good movies contained of meaningful morals. Our communities today have seen movies as their staple needs. No matter whether it is morning, afternoon, evening, or late night, watching does not make any significant trouble to their time. 
Indeed, it is already known and much appreciated that movie producers have managed the digitized moving pictures into an excellent visualization that can assembly the implicit meaning of the plot very well, for example the happy and sad emotion, suspense and dark atmosphere, a specific filter for different movie genre(s), and so forth. However, the semantic gap always exists when there is a misinterpretation during the watching process as the visual data collected into the watchers' mind (Vassiliou, 2006).

Most movies can be analyzed more completely to uncover further dimensions of importance. A movie review commonly incorporates individual impressions and assessments of a motion picture's substance and strategies. A decent review might be abstract, yet still touch externally on themes that may be investigated in more detail in a more extended formal examination. Meanwhile, an analysis attempts to decide how the film really utilizes different realistic systems and components of film or account structure to influence a watcher to respond with a specific goal in mind and why it makes watchers leave away with specific conclusions about it.

A good film analysis, regardless of whether expositions composed for magazines, diaries, books, or class assignments, endeavors to investigate films, instead of giving basic portrayals of what occurs. An examination requires some in-depth knowledge considered the film, and typically profits by different viewings and outside research. Most movies incorporate lines of exchange and delineate evident improvements of character that expressly convey significance to the watchers. Express substance is maybe a type of moral of the story. On the other hand, socio-political frame of mind that the movie producer is communicating specifically through the mouths and activities of the characters. As the plot creates the realisms, it additionally expresses close frames of mind about existence of culture (Jacobs, 2009).

A somewhat more profound dimension of understanding is verifiable substance, which might be more subtle yet can at present be induced by perceiving how the characters change, develop, and create over the span of a film. Jacobs (2009) further describes that issues and thoughts managing general human relations (instead of those particular to singular characters) might be genuinely simple to perceive however are not unequivocally expressed by the characters. Once in a while it is understood through implications, and distinctive watchers may translate a similar thing in various ways, regarding their own encounters and desires.

Bellour (2000) claimed that the process of movie analysis is more textually focused on the text because it always analyzes. Movie analysis is a product in which a movie is based on text and from there a text is formed. This is a specific process which is the first and foremost determined by the words. In this sense, it clearly has a way in common development that is often called textual analysis. The analysis of texts relies on the tradition conveyed in them.

Wildfeuer and Bateman (2016) also asserted that textual analysis has become a remarkable thing in cinema studies. It is the right action in the process of physical and material analysis that is delivered into a play. This analysis is in fact less used to analyze literary works presented in literary, mythical or painting texts and is more often qualified by appropriate methods and their terms of reference with the author's name. These designations are 
also served to characterize these filmic analyses, but they are soon incorporated into more general and more concrete textual analysis terminology.

For literary analysis, Brundage and Lahey (2011) demonstrated that literary analysis examines how prose fiction, poetry, drama, and movie perform as a special rhetoric for expressing meaning. Literary analysis most often focuses on the analysis of fiction, poetry, drama and movie. It is a natural analytical process for showing the expression of movie and history without mentioning the classical or medieval tradition. Literary analysis can also broaden its interest in topics and meanings beyond the movie discussed. The analytical process is sharpened by involving the relationship between the work and its author, audience, historical time and place, and culture.

This analytical process also analyzes the relationship between literary works and many other areas of knowledge in general. Concerning to the concept of hero and social status, the chronicled pertinence serves differently of every one among movies to the time. Each film compared to its chronicled. From multiple points of view each mirrored the sentiments of the specific administrative framework onscreen depiction of heroes and non-heroes and how the characters translated the occasions in which they are involved. Each film was a critique on the way of life and the social modalities towards war in the time that it was made, which positively makes sense since nothing occurs in a vacuum.

There will dependably be outside impacts on media substance and group of onscreen recognition. For this situation the verifiable and social setting in which the movies occurred were reflected inside the film's substance. While the courageous original remains constant all through the movies, the new definition has taken on a more human trademark than its antecedents. We can add to the present meaning of saint: he has lost the god-like qualities and battles with the issues of a conventional individual (Davie, 2011).

It is very obvious that audiences watch movies in many different ways. Realism is not only an absolute quality or quantity that we can understand and examine but also how members of the audience look at the movies that have realism or reality status (Rethel, 2015). Therefore, the intrinsic link to the audience is a key point and the question of how we as an individual audience understand different movies and appreciate the same movie differently. Some of the movies used to look realistic because they reflect the time and now they no longer do. Rethel (2015) also pointed out that realism and how the audiences read it represent especially for a particular historical moment in socio-political and cultural life. Realism is the effect that filmmakers and programs build on, whether it is mindful or not and it is not a illustration of the world, but the development that has to be worked on with great difficulty.

There are seven codes of realism in movie based on Ellis (1982). These codes have mutual connection, as follows: (1) The Code of Surface Realism is derived from John Ellis's taxonomy which is the weakest category of realism; (2) The Code of Social or Documentary Realism is involved by a fictitious representation that claims to show the unadorned world to say it as it is. (3) The Genre Code Criterion is crucial to the way ideas or realism depend on audience expectations; (4) The narrative code must clarify the audience and the events should always be seen as unexplained and related to each other in 
representation; (5) The Code of Psychology and Character Motivation lies ahead when the viewer concerns greater realism in the psychology of fictional characters and with fewer implications on some other codes; (6) The Code of Discursive or Ideological Truth focuses on movie where personal identity questions are related to messages and values of power or lack of power in society; and (7) The Counter-Realism Code of Institutional Constraint may seem somewhat tongue-in-check to provide a counter-realism code as a way of understanding realism and how viewers read the text that drives the code of realism.

Moreover, Campbell (2010) stated that local or regional literary colors were fiction and poetry that focus on character, dialect customs, topography, and other features especially for specific areas. This was influenced by Southwestern and Down East humor, between the Civil War and the late nineteenth century (Nowak, 2010) and this way of writing became dominant in American literature. Local colors did not only play a big role in the past but can also be found in this era. Petta and Trappl (2001) claimed the role of Fate Contrast was focused on changing the fate of roles during film progress and reflection in color change. It is possible to specify a distinctive color for multiple roles throughout the film. In this situation, different colors are required in different scenes for the same role.

In addition, a more critical look in the background of film making and media science uncovers that the outfits utilized in film creations are results of a mind boggling development process. The ensemble planner needs to put a ton of inventive and insightful exertion into the production of outfits to give the correct garments to a specific job, which implies the ensemble mirrors the spot and time of play just as it indicates comprehension of the attributes of the job, on-screen character and screenplay generally speaking. Thus, the formation of an ensemble is a troublesome issue that is pretty much happening frequently, though the recurrence of issue event emphatically depends on the class and points of interest of the film.

For the class of Western movies, for instance, the outfit of a Wild West Sheriff is met all requirements for distinguishing proof and portrayal as an example since it shows up often. In this paper, we propose an example language for making outfit designs through a rich arrangement of organization administrators, all the more fine-grained ensemble examples, and outfit natives. The example language goes for supporting media science, outfit plan, and ensemble the board through giving a premise to the improvement of cutting edge data frameworks helping the administration of outfits considering their innate structure and relations between their constituent parts. Our example approach is exemplified through profound plunge demonstrating of two ensemble designs (Schumm, et al, 2012).

Moreover, Thread Phase Contrast also focuses on the color changes that describe the progress of the plot in a movie. While the role of the Fate Contrast explains the role of color change throughout the film, the contrast phase of the thread suggests on the scene color change in the film (Petta \& Trappl, 2001). There are three phases giving values of three different colors in the movie, such as the happy phase for the birth of the lion prince, the survivors of many animals; the sorrows phase for death of the old lion king and a new happy phase for coronation of the new lion king. 
Kupfer (2014) presented the meta-narrative concept in movie has a predetermined meaning other than the one used here. It focuses on movie stories that draw attention to the meta-narrative that explains the story and story-telling story in daily life. The story of the movie itself is no problem, following the straight narrative line consisting of plot, character and distinctive dialogue. Something to make a movie become extraordinary is the important stories delivered in human life resulting in the aesthetic experience.

Initially, we assume that the movie narrative comes in many physical forms (conversation, pictures, dance, and music) and the narrative of movie has top-down cognitive effect. Martin (1994) also verified that the movie narrative can be sources of visual sources from the movie, and not only conversely. Nevertheless, it can be learned by concentrating on top-down processes in an effort to separate the psychological aspect that enables the narratives to be comprehended in all media.

Ahrens (2000) asserted that the symbols in movie can have an effect on the interface between fiction and reality and thus help to express the fact of the unconscious mind. It can help to encourage the audience involvement and emotional engagement in the story which is essential to promote the specific result. Several movies have full of hidden symbols and meanings which make the movies are difficult to analyze. None interpretation is very suitable and makes symbolic coherence.

Therefore, they also have multiple interpretations, none of which match all the parts and aspects of the movie. Symbolism also describes the modern literature through several fields, as follows the introduction of free, free verses and free rhythm which is the rhythm organized by the author's psychological disposition rather than the prosody canonical disposition (Balla, 2012). In any case, not only does symbolism lay the foundations of human culture in general but it also carries considerable contributions to modern literature and culture.

This study triesto revoke the essence of a literature movie to see aspects that are contained of realism, local color, narratives, and symbolism. The movie called "Sense and Sensibility", which is the original title of the novel also called "Sense and Sensibility" wirtten by Jane Austen in 1811. The movie was later produced in 1995 by Mirage Enterprises and directed by Ang Lee. The movie is about the Dashwood family.

\section{METHOD}

The method used in this study was moral-philosophical approach (Herlina, 2016) that focused on finding out the moral values of the literary works, and in this case is movie. The primary data is the movie itself played within a hundred and forty minutes. The information obtained were then classified into components such as realism, local color, narratives, and symbolism. The movie is based on a novel written by Jane Austin entitled also "Sense and Sensibility". The movie was watched for several times to carefully extract the essences that could be found in it. Later, after obtaining the data, the classification was carried out. 


\section{RESULTS AND DISCUSSION The summary of the movie}

Elinor Dashwood was a humble and generous daughter from a noble family in Norland, somewhere in England, but has to move out to Devonshire and overwhelmed all wealth to her uncle as soon as her father's died because there was no son in their family which meant no heir. Her mother is also a loving woman who cares so much for her daughters-Elinor, the eldest, Marianne, the second daughter who was so lovelorn that she was just 17-year-old and Margaret, who was still very young and impassionate on life. She finds it hard to live their life in the countryland at first, but they did manage becuase there was a kind family, Ms. Jenning's, who is always in eagerness to help the Dashwoods. Edward Fellars, who is a foster-brother of Jenny, her uncle's wife, is apparently in love with Elinor even from the first time they meet in Norland by the time her familiy was about to leave the house.

There is another character, who is Elinor's sister named Marianne. There was a party at Ms. Jenning's in where Elinor and her sisters as well as her mother came over to. They were dancing on the dancefloor as her sister, Marianne, met a pair for Willoughby-an immensely enchanting noble gentleman who was indeed a seducer. In the greenness of Devonshire they wove their love as if nothing could put it to an end but Elinor was quite offensive, though. She was worrisome that their destitution at that time would lead to her sister's heartache, and unluckily it led there.

The young blooming Marianne fell so hard as she knew that Willoughby would leave Devonshire and run a business in London-of which the truth is his aunt had known his affair to Marianne and dumped him for her heritage, so he had to find somenone prosperous to be married to in London. And Eleanor herself, found Edward came to visit them, and hope that he would propose but caught Edward's ring in which was kept someone's hair. As she visited the Steels, shockingly, she later knew that he was secretly engaged to Lucy Steel, Ms. Jenning's niece, and her heart was in ache but she concealed it all unspoken. Then, she visited London to find Willoughby.

Ms. Jenning asks for the Dashwood girls' companionship to London and Elinor and Marriane agree to accompany her. Elinor and her sister, Marianne, go to London and stay in Ms. Jenning's flat. Marianne writes to Willoughby at once on the insistence to meet him, but no replies at all. Finally, they are informed that there will be a dinner assembly at downtown wher e Willoughby and Edward will be there. Marianne does meet Willoughby but she is rudely ignored by him.

Now she is heart-broken and nothing she can do but wailing. Elinor whose heart is also in mourn can just pervade her sister's pain and conceals hers. As they stay for some times in London, she is again informed that Edward-Lucy relationship has reached a consent from Edwrad's family and they are looking forward to marrying. In this turn, Eleanor can not bear her pain any longer so that later Marianne notices she is weeping and telling her everything, the pain she has harbored for months. However, she clarifies that she is truly happy for Edward and decided to forget everything about him.

Marianne, is such a young lady who cannot take this fact again and again, she is desperate and tortures herself in a rainy and thundery evening. Luckily Colonel Brandon-who is apparently possessed such deep love for 
her-saves her and holds her back to the apartment and is extremely worried about her. A doctor comes to treat her an figures out that Marianne has a sort of lung disease that might possibly putrify her lungs. While she is in bed restarining her illness, Willoughby comes over and is harshly welcomed by Elinor although he comes for apology.

Colonel Brandon fetches Mrs. Dashwood to London and fortunately Marianne recovers her illness before all of them returned to Devonshire. As soon as they are back to Devonshire, Marianne spends more time with Colonel Brandon as she is allowed to come to his library to read books and to play his piano-of which Marianne is so fond as she wants to be a musician and she is good at playing it. The days pass by and she finds that eventually her feelings to him changed and she starts to love him. As her sister sights for her true love in Colonel Brandon toward marriage, Eleanor mistakenly hears that Lucy Steel is married to Edward Ferrars.

She tries to let her feeling go and attempts to be happy still for Marianne, she is later notified by Margaret's shout that Edward is coming. Then the truth reveals that the one who is married to Lucy Steel is Robert Ferrars, his brother, and now he comes to Devonshire to ask Elinor's hand for a ring. Elinor is so blasted in tears of bliss that she can not bear upon she is proposed for real by her beloved, Edward Ferrars.

\section{Discussion}

In this movie, first, the character of Elinor shows that the character is idyllic enough to be realistic, other characters are so natural that they face life as it can be accepted nowadays. Second, the value that the noble rich families have against the destitute-of which prosperity, wealth, and social position determine the fidelity of love-is somewhat unrealistic today. Last, it can hardly be taken into account that the Dashwoods permeated every single bad thing happened to them without no ventures. The realism implied in this movie is classified to be The Code of Discursive or Ideological Truth in Ellis (1982) taxonomy. Itfocuses on picture wherever identity queries are associated with messages and values of power or lack of power in a certain society. In this case, it is Elinor who has no power at all after her family's wealth gone.

Next, there are three local colors presented in this movie. First, the costumes are identically realistic with the mid-eighteenth fashion in where English still wore such kingdom-some costumes, as well as the carriages. It is difficult to give proof to hypotheses in media science identified with outfits in movies. For instance, how might one be able to approve the supposition that there are 'stereotyped outfits' that enable a specific gathering of people to rapidly comprehend the job of a supporting on-screen character just by observing him for a brief timeframe? With an organized group for ensembles we might want to give another approach to approving such suspicions (Schumm, et al, 2012).

By centering as it were on a specific film class and time and using reflection we go for distinguishing examples of ensembles and basically portraying them. For this, an ensemble design language is required, of which we present an underlying representation in this paper. Be that as it may, this language is the perfect begin for research in correspondence that depends on data innovation for the humanities. 
We imagine a vast index of outfits and ensemble designs that can be examined by media researchers to make new learning and knowledge by applying procedures like information mining and measurable announcing, for instance to break down the recurrence of a specific blend of bits of apparel in a specific kind. An inquiry that can be replied through data innovation is, for example, how settled traditions of attire in movies changed after some time. The appropriate response a framework may give would be somewhat auxiliary and numerical, which is another method for media science inquire about in this field.

Next, the better position in the army is the better job in the society. Films are from numerous points of view an artistic expression and furthermore a type of mass correspondence that has the ability to persuade and move the gathering of people inwardly. Billions of dollars are paid every year by crowds to head out to the films and experience stories they have not lived themselves. Films expect a vocation in our overall population that some consider comparably as basic as the evening news or a system appear. Everyone can name no short of what one film that affected him/her on a significant measurement.

The truth is that film is a champion among the most basic kinds of mass correspondence and the subjects, prime precedents and characters it portrays are deciphered by an immense number of people each and every week's end. Film is such a basic kind of mass correspondence since it accomplishes the tremendous number of movie goers reliably who decipher the subjects, models, and characters portrayed. The depictions in film have a relationship with our overall population and culture. A progressively significant appreciation of this kind of media could propel our comprehension into the portrayals of legend warriors, disentangle their relationship with our overall population, and research the suggestions they hold (Davie, 2014).

Then, wealth is belonged to women, that is why both Willoughby and Edward are dismissed from the inheritage by his aunt, and his mother, respectively. Then, the narrative of this story is told in a linear plot starting the time they live in Devonshire upon Marianne's falling in love, but numbers of flashback intervened the story when Elinor recalled all the memories within her father's death until the Devonshire settlement. After that, it goes forward again telling how the harsh life finally rewarded with blessedness.

Regarding to the symbolism, this story is bulkily simbolized by the condition of the nature-country and city, Devonshire and London. In Devoshire where the greenness of the country, the soothing breeze, also the sobriety of the flowing rivers, did happen merciful events such as Marianne fell in love with Willoughby, Marianne wove her love again-after recovering-with Colonel Brandon, and Elinor's marriage proposal from Edward. Meanwhile, in the bustle of London, its rush of parties, and laughters of those heartless capitalists, all ungratified events occured namely; Marianne's refused by Willoughby, Marianne's lung-disease, Elinor's knew that Edward was secretly enganged to Lucy Steel, Elinor had to see her family life being wrecked by those rich people who count more on wealth rather than love and kindness. As Ahren (2000) asserts that the symbols in movie will have an impression on the interface between fiction and reality and therefore facilitate to specify the actual fact of the unconscious mind of the author. 


\section{CONCLUSION}

From the results, it can be concluded that this movie basically conceives the moral values telling that people should strongly strive in life. It presents various life problems such as love, property, and family problems. The realism shows that there are royal people who can fail life and struggle like working class people, then local color shows that in mid-eighteenth era, the position in army determined the social status, and wealth was controlled by women. And finally, the movie lanscape engraves that Devonshire is such a soothing and alleviating nature that goes well with the movie's melancholia.

\section{REFERENCES}

Ahrens, R. (2000). Symbolism: Vol 1: A New International Journal of Critical Aesthetics. New York: AMS.

Balla, B. (2012). Symbolism, Synesthesia, and Semiotics, Multidisciplinary Approach. Bloomington: Xlibris Corporation.

Bellour, Raymond. (2000). The Analysis of Film. Bloomington: Indiana University Press.

Brundage, D., \& Lahey, M. (2011). Acting on Words: An Integrated Rhetoric, Reader and Handbook. London: Pearson Education.

Campbell, D. M. (2010). Regionalism and Local Color Fiction. Athens: Ohio University Press.

Davie, G. S. (2011). The Hero Soldier: Portrayals of Soldiers in War Films. Unpublished master thesis. University of South Florida, Tampa.

Ellis, J. (1982). Visible Fictions: Cinema, Television, Video. 1982. London: Routledge \& Kegan Paul.

Herlina, N. (2016). Teaching literature through poetry: A shifting reading orientation from efferent to aesthetic. Edulite: Journal of English Education, Literature, and Culture. Vol.1, No. 2. DOI: http://dx.doi.org/10.30659/e.1.2.225-238.

Jacobs, C. P. (2009). Film Theory and Approaches to Criticism. Oxford: Oxford University Press.

Kupfer., J. (2014). Meta-Narrative in the Movies. London: Palgrave Macmillan.

Martin, W. (1994). Recent Theories of Narrative. New York: Cornell University Press.

Nowak, T. (2010). Why Can the Movie "8 Mile" be Considered a Local Color Story?. Norderstedt: GRIN Verlag.

Petta, J., \& Trappl, R. (2001). Emotions and Agents. In M. Luck, V. Marik, O. Stepankova, R. Trappl (Ed.), Multi-Agent Systems and Applications (pp. 301-316). Berlin: Springer. 
Rethel, M. S. (2015). Real to Reel: A New Approach to Understanding Realism in Film and TV Fiction. Leighton Buzzard: Auteur Publishing.

Schumm, D., Barzen, J., Leymann, F., and Ellrich., L. (2012). A pattern for language costumes in films. the Proceedings of the 17th European Conference on Pattern Languages of Programs, Stuttgart, Germany.

Vassiliou, A. (2006). Analysing film content: A text-based approach. Unpublished doctoral dissertation. University of Surrey, Guildford, Surrey.

Wildfeuer, J., \& Bateman, J. A. (2017). Introduction: Bringing Together New Perspectives on Film Text Analysis. In J. Wildfeur \& J. A. Bateman (Ed.), Film Text Analysis: New Perspectives on the Analysis of Filmic Meaning (pp. 3-18). Oxon: Taylor \& Francis. 